\title{
UJI AKTIVITAS ANTIOKSIDAN MASERAT AIR BIJI KOPI (Coffea canephora) HIJAU PUPUAN DENGAN METODE DPPH (2,2-difenil-1-pikrilhidrazil)
}

\section{(PUPUAN GREEN COFFEE BEAN (Coffea canephora) WATER MACERATE ANTIOXIDANT ACTIVITY TEST USING DPPH METHOD (2,2-diphenyl-1-pikrilhidrazil))}

\author{
NI MADE DHARMA SHANTINI SUENA ${ }^{1 \bullet}$, NI PUTU UDAYANA ANTARI ${ }^{1}$ \\ ${ }^{1}$ Fakultas Farmasi Universitas Mahasaraswati Denpasar \\ Jalan Kamboja No.11A, Denpasar Utara, Bali
}

\begin{abstract}
Abstrak: Antioksidan dapat membantu melindungi tubuh dari serangan radikal bebas dan meredam dampak negatifnya. Indonesia memiliki keragaman tanaman buah yang memiliki manfaat sebagai antioksidan. Pupuan adalah daerah penghasil kopi robusta (Coffea canephora) di Bali yang dinilai memiliki pengelolaan produksi hingga panen yang baik. Senyawa asam klorogenat larut dalam air dan berfungsi sebagai antioksidan. Biji kopi hijau robusta paling banyak mengandung asam klorogenat dibandingkan dengan biji kopi lainnya. Maka dilakukan pengujian terhadap aktivitas antioksidan maserat air biji kopi hijau robusta daerah Pupuan dengan menggunakan metode DPPH (2,2-difenil-1-pikrilhidrakzil). Serbuk simplisia biji kopi hijau robusta dimaserasi dengan bantuan gelombang ultrasonik menggunakan pelarut air (1:3), kemudian difiltrasi dengan bantuan mesh dan Corong Buchner. Maserat air biji kopi hijau robusta diendapkan selama 24 jam, kemudian dipisahkan antara filtrat dan endapan. Setelah itu diuji aktivitas antioksidan dari filtrat dan endapan maserat air biji kopi hijau robusta dengan metode DPPH secara Spektrofotometri UV-Vis. Nilai IC $_{50}$ filtrat dan endapan maserat air biji kopi hijau robusta berturut-turut adalah $262,41 \mathrm{ppm}$ dan $244,42 \mathrm{ppm}$. Filtrat maserat air tergolong memiliki aktivitas antioksidan yang lemah dan endapan maserat air tergolong memiliki aktivitas antioksidan yang sedang. Dari hasil uji aktivitas antioksidan dengan metode DPPH maka dapat disimpulkan bahwa maserat air biji kopi hijau robusta di daerah Pupuan memiliki aktivitas antioksidan.
\end{abstract}

Kata kunci: antioksidan, biji kopi hijau, maserat air, metode DPPH.

Abstract: Antioxidants can help protect the body from free radical attack and reduce its negative effects. Indonesia has a diversity of fruit plants that have antioxidant benefits. Pupuan is a Robusta coffee producer (Coffea canephora) in Bali which is considered to have good production management to harvest. Chlorogenic acid compounds dissolve in water and function as antioxidants. Robusta green coffee bean contain the most chlorogenic acid compared to other coffee beans. Then the water macerate of Robusta green coffee bean in Pupuan area was tested for its antioxidant activity using the DPPH method (2,2-diphenyl-1-picrylhydrakzil). The simplicia powder of Robusta green coffee beans is macerated with the aid of ultrasonic waves using water (1:3) solvent, then filtered with the help of a mesh and a funnel Buchner. The water macerate of Robusta green coffee bean was deposited for 24 hours, then separated between the filtrate and sediment. After that, the antioxidant activity of the filtrate and sediment of Robusta green coffee bean water macerate were tested using the DPPH method using UV-Vis spectrophotometry. The $\mathrm{IC}_{50}$ values of filtrate and sediment of Robusta green coffee bean water macerate were $262.41 \mathrm{ppm}$ and $244.42 \mathrm{ppm}$, respectively. Water macerate filtrate is classified as having weak antioxidant activity and water macerate sediment are classified as having moderate antioxidant activity. From the results of the antioxidant activity test using the DPPH method, it can be concluded that the water macerate of Robusta green coffee bean in the Pupuan area has antioxidant activity. Key words: antioxidants, DPPH method, green coffee bean, water macerate.

\section{PENDAHULUAN}

Setiap mahluk hidup atau organisme akan sampai pada proses menjadi tua. Proses tua tersebut memang normal terjadi dan tidak dapat dihindari. Proses tua dianggap sebagai siklus hidup yang normal bila datangnya tepat waktu. Sayangnya, terkadang terjadi proses penuaan dini yang terlalu cepat (Zuhra et al., 2008). Salah satu penyebab dari proses penuaan dini adalah radikal bebas.
Dampak reaktivitas senyawa radikal bebas bermacam-macam, mulai dari kerusakan sel atau jaringan, penyakit autoimun, penyakit degeneratif, hingga kanker. Tanpa disadari, dalam tubuh kita terbentuk radikal bebas secara terus menerus, baik melalui proses metabolisme sel normal, peradangan, kekurangan gizi, dan akibat respons terhadap pengaruh dari luar tubuh, seperti polusi lingkungan, ultraviolet (UV), asap rokok, dan lainlain (Winarsi, 2005).

•email korespondensi: dharmashantini@unmas.ac.id 
Tubuh kita memerlukan suatu substansi penting yakni antioksidan yang dapat membantu melindungi tubuh dari serangan radikal bebas dan meredam dampak negatifnya. Antioksidan merupakan senyawa yang dapat menghambat reaksi oksidasi, dengan mengikat radikal bebas dan molekul yang sangat reaktif. Akibatnya, kerusakan sel akan dihambat (Winarsi, 2005).

Manusia memiliki antioksidan dalam tubuh, namun jumlahnya tidak mencukupi untuk mengatasi radikal bebas yang berlebih sehingga dibutuhkan antioksidan eksogen. Antioksidan eksogen dibagi menjadi 2 berdasarkan sumbernya, yaitu antioksidan alami dan antioksidan sintetik (Hani \& Milanda, 2016). Beberapa contoh antioksidan sintetik dapat memiliki efek karsinogenesis sehingga penggunaan antioksidan alami mengalami peningkatan (Hani \& Milanda, 2016).

Indonesia merupakan salah satu negara yang memiliki keragaman tanaman buah. Tingginya keragaman tanaman buah tersebut menghasilkan berbagai manfaat untuk kesehatan, salah satunya antioksidan (Hani \& Milanda, 2016). Indonesia merupakan produsen kopi terbesar ke-4 di dunia dan masuk dalam 5 negara konsumen kopi terbesar. Pupuan adalah daerah penghasil kopi robusta (Coffea canephora) di Bali. Predikat Indikasi Geografis dari Kementerian Hukum dan HAM RI disandang kopi robusta (Coffea canephora) Pupuan karena dinilai memiliki pengelolaan produksi hingga panen yang baik (Kristianto, 2017) (Kristianto, 2017).

Kopi mengandung senyawa kimia seperti kafein, asam klorogenat, trigonelin, karbohidrat, lemak, asam amino, asam organik dan aroma volatile (Farhaty \& Muchtaridi, 2016). Manfaat asam klorogenat bagi kesehatan manusia yaitu sebagai antioksidan, antivirus, hepatoprotektif, dan berperan dalam kegiatan antispasmodik (Farah \& Donangelo, 2006). Asam klorogenat adalah suatu senyawa yang termasuk ke dalam komponen fenolik, mempunyai sifat yang larut dalam air (Farhaty \& Muchtaridi, 2016). Biji kopi hijau robusta paling banyak mengandung asam klorogenat dibandingkan dengan biji kopi lainnya (Farah, 2012). Pada setiap daerah, biji kopi memberikan nilai kandungan asam klorogenat yang berbeda (Farhaty \& Muchtaridi, 2016). Biji kopi hijau adalah biji kopi yang tidak melalui proses penyangraian (Farah, 2012).

Ekstrak etanol biji kopi hijau memiliki aktivitas antioksidan yang tinggi. Didapatkan hasil bahwa ekstrak etanol dari biji kopi hijau memiliki kemampuan menangkap radikal bebas DPPH (2,2difenil-1-pikrilhidrakzil) sebesar $70,4 \%$ pada 50 $\mu \mathrm{M}$ yang dibandingkan dengan asam askorbat (penghambatan $86,1 \%$ pada $50 \mu \mathrm{M})($ Almoosawi et al., 2010).

Sehubungan dengan hal tersebut, maka dilakukan pengujian terhadap aktivitas antioksidan menggunakan metode DPPH (2,2-difenil-1pikrilhidrakzil) dari maserat air biji kopi hijau robusta daerah Pupuan.

\section{METODE PENELITIAN}

\section{Rancangan Penelitian}

Jenis/desain penelitian. Jenis penelitian ini adalah ekperimental dengan rancangan penelitian Post Test Only Design yang bertujuan untuk mengetahui aktivitas antioksidan berdasarkan nilai $\mathrm{IC}_{50}$ dari filtrat dan endapan maserat air biji kopi hijau robusta dengan metode DPPH secara Spektrofotometri UV-Vis.

\section{Teknik pengumpulan data}

Pengumpulan biji kopi hijau robusta. Biji kopi hijau robusta (Coffea canephora) diperoleh dari Desa Pajaan, Pupuan, Tabanan, Bali pada bulan November 2018. Kopi dipanen oleh petani pada bulan Agustus 2018 pada siang hari.

Determinasi tanaman. Tanaman kopi robusta (Coffea canephora) yang digunakan untuk determinasi adalah tanaman muda utuh. Determinasi tanaman dilakukan di Lembaga Ilmu Pengetahuan Indonesia Balai Konservasi Tumbuhan Kebun Raya "Eka Karya" Bedugul, Bali.

Penyiapan simplisia. Biji kopi hijau robusta disortasi kering, kemudian ditimbang dengan timbangan digital, lalu dikeringkan dalam oven pada suhu $40^{\circ} \mathrm{C}$. Ditimbang setiap 24 jam sekali hingga mendapatkan bobot penimbangan yang konstan sebanyak 3 kali penimbangan. Lalu dihaluskan dengan cara ditumbuk dan menggunakan blender. Serbuk simplisia disimpan dalam wadah topless kaca tertutup rapat dan ditempatkan pada suhu ruangan serta terhindar dari cahaya matahari langsung.

\section{Pembuatan maserat air biji kopi hijau robusta}

1. Disiapkan alat dan bahan yang akan digunakan.

2. Ditimbang 150 gram serbuk simplisia biji kopi hijau robusta.

3. Diukur $450 \mathrm{ml}$ volume aquadest.

4. Dimasukkan 150 gram serbuk simplisia biji kopi hijau robusta ke dalam beaker glass, ditambahkan $450 \mathrm{ml}$ aquadest. 
5. Diaduk hingga serbuk simplisia terendam oleh pelarut, kemudian diletakkan di atas alat Elmasonic $^{\circledR}$.

6. Alat Elmasonic ${ }^{\circledR}$ dihidupkan, kemudian diatur suhu $40^{\circ} \mathrm{C}$ selama 3 menit. Setelah itu diaduk selama 5 menit. Hal ini diulangi sebanyak 3 kali.

7. Setelah itu disaring menggunakan Mesh 60, 80 dan 100. Hasil saringan difiltrasi kembali dengan bantuan Corong Buchner.

\section{Pembuatan filtrat dan endapan maserat air biji} kopi hijau robusta. Maserat air biji kopi hijau robusta diendapkan selama 24 jam, kemudian dipisahkan antara filtrat dan endapan.

Pengujian aktivitas antioksidan. Pengujian filtrat dan endapan maserat air biji kopi hijau robusta dilakukan dengan tahapan sebagai berikut :

1. Pembuatan Larutan Induk filtrat dan endapan maserat air biji kopi hijau robusta konsentrasi $1000 \mathrm{ppm}$

Larutan induk $1000 \mathrm{ppm}$ dibuat dengan cara menimbang $100 \mathrm{mg}$ filtrat dan endapan maserat air biji kopi hijau robusta, kemudian masing - masing dilarutkan dengan etanol 96\% sampai tanda batas dalam labu ukur $100 \mathrm{ml}$, dikocok hingga homogen.

2. Pembuatan Larutan Uji Konsentrasi 100 ppm Pembuatan larutan uji dengan konsentrasi 100 ppm dibuat dengan cara masing-masing larutan induk filtrat dan endapan maserat air biji kopi hijau robusta 1000 ppm dipipet sebanyak $5 \mathrm{ml}$, kemudian masing-masing dimasukkan ke dalam labu ukur $50 \mathrm{ml}$, ditambahkan etanol 96\% sampai tanda batas. Kemudian dikocok sampai homogen.

3. Pembuatan Larutan Uji Konsentrasi 20, 40, 60, dan 80 ppm

Pembuatan larutan uji dengan konsentrasi 20, 40, 60, dan 80 ppm dibuat dengan cara masingmasing larutan uji filtrat dan endapan maserat air biji kopi hijau robusta konsentrasi 100 ppm dipipet sebanyak 2, 4, 6 dan $8 \mathrm{ml}$, kemudian masing-masing dimasukkan ke dalam labu ukur $10 \mathrm{ml}$, ditambahkan etanol $96 \%$ sampai tanda batas. Kemudian dikocok sampai homogen.

4. Pembuatan Larutan Baku Induk DPPH Konsentrasi 100 ppm

Pembuatan larutan baku induk DPPH konsentrasi 100 ppm dibuat dengan cara ditimbang $10 \mathrm{mg}$ serbuk DPPH, kemudian dilarutkan dengan etanol 96\% dalam labu ukur $100 \mathrm{ml}$ sampai tanda batas, dikocok hingga homogen.
5. Pembuatan Larutan Baku Kerja DPPH Konsentrasi 40 ppm

Pembuatan larutan baku kerja DPPH konsentrasi 40 ppm dibuat dengan cara larutan baku DPPH konsentrasi 100 ppm dipipet sebanyak $20 \mathrm{ml}$, dimasukkan ke dalam labu ukur $50 \mathrm{ml}$ kemudian ditambah etanol $96 \%$ sampai tanda batas. Kocok sampai homogen.

6. Penentuan Panjang Gelombang Maksimum Larutan Baku DPPH 40 ppm

Penentuan Panjang Gelombang Maksimum Larutan Baku DPPH 40 ppm, dilakukan dengan cara larutan baku DPPH $40 \mathrm{ppm}$ dipipet sebanyak $4 \mathrm{ml}$ dimasukan ke dalam kuvet, lalu diamati spektrum serapannya pada panjang gelombang 400-800 nm dengan spektrofotometer UV-Vis. Untuk larutan blanko digunakan $4 \mathrm{ml}$ etanol 96\%. Dari kurva serapan dapat ditentukan panjang gelombang maksimum.

7. Pengukuran Absorbansi DPPH

Pengukuran absorbansi DPPH dilakukan dengan cara larutan DPPH 40 ppm dipipet sebanyak $2 \mathrm{ml}$, dimasukkan ke dalam tabung reaksi, ditambah $2 \mathrm{ml}$ etanol 96\%, divortex dan didiamkan selama 30 menit selanjutnya dimasukan ke dalam kuvet, kemudian diamati dengan spektrofotometer UV-Vis absorbansinya pada panjang gelombang maksimum.

8. Pengukuran Aktivitas Peredaman Radikal Bebas:

Pengukuran aktivitas peredaman radikal bebas dilakukan dengan cara larutan DPPH 40 ppm dipipet sebanyak $2 \mathrm{ml}$, dimasukan ke dalam tabung reaksi, ditambah $2 \mathrm{ml}$ larutan uji dari masing-masing konsentrasi $(20 ; 40 ; 60 ; 80$; dan $100 \mathrm{ppm}$ ), divortex dan didiamkan selama 30 menit. Setelah itu diamati absorbansinya pada panjang gelombang maksimum dengan Spektrofotometer UV-Vis secara bergantian pada kelima konsentrasi. Absorbansi masingmasing dicatat. Kemudian dari absorbansi tersebut dilakukan perhitungan persentase peredaman dengan rumus:

$\%$ peredaman $=\frac{\text { absorbansi DPPH }- \text { absorbansi sampel uji }}{\text { absorbansi DPPH }} \times 100 \%$

Dari nilai persentase peredaman pada masingmasing kosentrasi, selanjutnya dibuat kurva regresi, sehingga didapatkan persamaan $\mathrm{y}=\mathrm{bx}$ + a dan akan diperoleh nilai $I C_{50}$ dengan perhitungan secara regresi linier dimana konsentrasi sampel (ppm) sebagai absis $($ sumbu $x)$ dan nilai persentase peredaman sebagai ordinatnya (sumbu y). Nilai $\mathrm{IC}_{50}$ 
didapatkan dari perhitungan persen peredaman sebesar $50 \%$.

\section{Instrumen penelitian}

a. Alat

Alat yang digunakan dalam penelitian ini antara lain: timbangan digital (AciS BC$\left.6000^{\circledR}\right)$, oven $\left(\right.$ SOV $\left.70 \mathrm{~B}^{\circledR}\right)$, Elmasonic ${ }^{\circledR}$, loyang, tabung reaksi (Merck), pipet volume (Merck), labu ukur (Merck), corong Buchner (Merck), Spektrofotometer Uv-Vis double beam (Shimadzu/UV-1800 ${ }^{\circledR}$ ), alat-alat gelas umum yang ada di Laboratorium Terpadu Fakultas Farmasi Universitas Mahasaraswati Denpasar.

b. Bahan

Bahan yang digunakan dalam penelitian ini antara lain biji kopi hijau robusta, aquadest, serbuk DPPH (Sigma Aldrich ${ }^{\circledR}$ ), etanol 96\% (Merck).

\section{HASIL PENELITIAN}

\section{Hasil Uji Determinasi}

Pada penelitian ini digunakan tanaman kopi hijau robusta (Coffea canephora Pierre ex A.Froehner) yang dideterminasi dalam keadaan utuh dan segar. Identifikasi taksonomi tumbuhan dilakukan di LIPI Balai Konservasi Tumbuhan Kebun Raya "Eka Karya" Bali. Tanaman kopi hijau robusta termasuk dalam Famili Rubiaceae.

\section{Hasil Penentuan Panjang Gelombang Maksimum DPPH}

Hasil penentuan panjang gelombang maksimum DPPH dengan larutan DPPH 40 ppm yang diukur serapannya pada panjang gelombang 400-800 $\mathrm{nm}$ adalah $518 \mathrm{~nm}$.

\section{Hasil Uji Aktivitas Antioksidan}

Aktivitas Antioksidan Filtrat Maserat Air Biji Kopi Hijau Robusta

Tabel 1. Aktivitas Antioksidan Filtrat Maserat Air Biji Kopi Hijau Robusta

\begin{tabular}{|c|c|c|c|c|}
\hline $\begin{array}{c}\text { Konsentrasi } \\
\text { sampel } \\
(p p m)\end{array}$ & $\begin{array}{c}\text { Absorba } \\
\text { nsi } \\
\text { Kontrol }\end{array}$ & $\begin{array}{c}\text { Absorba } \\
\text { nsi } \\
\text { sampel } \\
\end{array}$ & $\begin{array}{c}\text { Peredam } \\
\text { an }(\%)\end{array}$ & $\begin{array}{c}\text { Persamaan } \\
\text { Regresi } \\
\text { Linier } \\
\end{array}$ \\
\hline 20 & \multirow{4}{*}{0,501} & 0,468 & 6,59 & \multirow{4}{*}{$\begin{array}{c}\mathrm{y}=0,176 \mathrm{x}+ \\
3,815 \\
\mathrm{r}^{2}=0,968\end{array}$} \\
\hline 60 & & 0,421 & 15,97 & \\
\hline 80 & & 0,412 & 17,76 & \\
\hline 100 & & 0,397 & 20,76 & \\
\hline
\end{tabular}

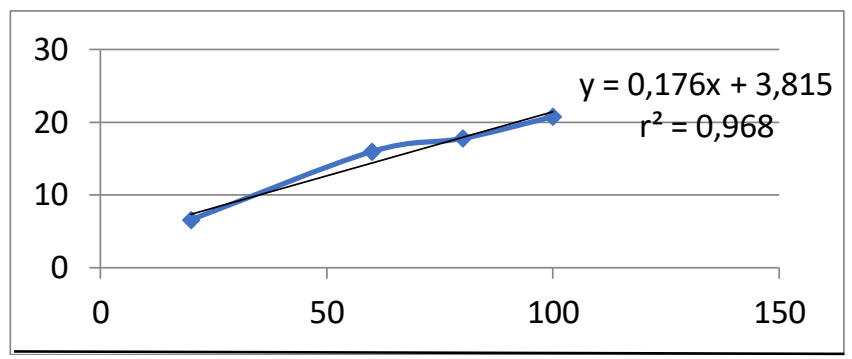

Gambar 1. Kurva Regresi Linier Aktivitas Antioksidan Filtrat Maserat Air Biji Kopi Hijau Robusta

Dari kurva regresi linier tersebut, maka dapat dihitung nilai $\mathrm{IC}_{50}$ dari filtrat maserat air biji kopi hijau robusta yaitu, sebagai berikut:

Perhitungan Nilai $\mathrm{IC}_{50}$ :

$y=b x+a$

$y=0,176 x+3,815$

$50=0,176 x+3,815$

$x=\frac{50-3,815}{0,176}$

$x=262,41 \mathrm{ppm}$

Jadi, nilai $\mathrm{IC}_{50}$ filtrat maserat air biji kopi hijau robusta adalah 262,41 ppm. Dari nilai $\mathrm{IC}_{50}$ yang diperoleh menunjukkan bahwa filtrat maserat air biji kopi hijau robusta memiliki aktivitas antioksidan yang lemah.

\section{Aktivitas Antioksidan Endapan Maserat Air Biji Kopi Hijau Robusta}

Tabel 2. Aktivitas Antioksidan Endapan Maserat Air Biji Kopi Hijau Robusta

\begin{tabular}{|c|c|c|c|c|}
\hline $\begin{array}{c}\text { Konsentrasi } \\
\text { sampel } \\
(\text { ppm) }\end{array}$ & $\begin{array}{c}\text { Absorbansi } \\
\text { Kontrol }\end{array}$ & $\begin{array}{c}\text { Absorbansi } \\
\text { sampel }\end{array}$ & $\begin{array}{c}\text { Peredaman } \\
(\%)\end{array}$ & $\begin{array}{c}\text { Persamaan } \\
\text { Regresi } \\
\text { Linier }\end{array}$ \\
\hline 20 & \multirow{4}{*}{0,492} & 0,444 & 9,76 & \multirow{4}{*}{$\begin{array}{c}y= \\
0,178 x+ \\
6,493 \\
r^{2}=0,982\end{array}$} \\
\hline 60 & & 0,421 & 14,43 & \\
\hline 80 & & 0,395 & 19,72 & \\
\hline 100 & & 0,369 & 25 & \\
\hline
\end{tabular}

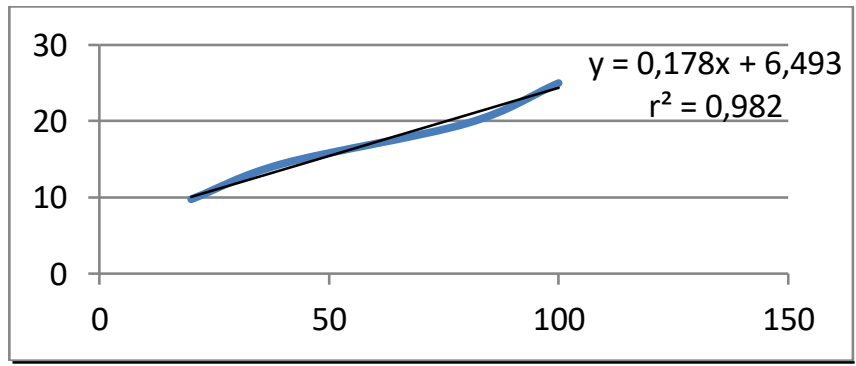

Gambar 2. Kurva Regresi Linier Aktivitas

Antioksidan Endapan Maserat Air Biji Kopi Hijau Robusta

Dari kurva regresi linier tersebut, maka dapat dihitung nilai $\mathrm{IC}_{50}$ dari endapan maserat biji kopi hijau robusta yaitu, sebagai berikut: 
Perhitungan Nilai $\mathrm{IC}_{50}$ :

$y=b x+a$

$y=0,178 x+6,493$

$50=0,178 x+6,493$

$x=\frac{50-6,493}{0,178}$

$x=244,42$ ppm

Jadi, nilai $\mathrm{IC}_{50}$ endapan maserat air biji kopi hijau robusta adalah 244,42 ppm. Dari nilai $\mathrm{IC}_{50}$ yang diperoleh menunjukkan bahwa endapan maserat air biji kopi hijau robusta memiliki aktivitas antioksidan sedang.

\section{PEMBAHASAN}

Pengujian aktivitas antioksidan pada filtrat dan endapan dari maserat air biji kopi hijau robusta dilakukan dengan metode pengujian menggunakan 2,2-difenil-1-pikrilhidrazil (DPPH). Metode uji antioksidan menggunakan DPPH adalah salah satu metode uji kuantitatif untuk menentukan daya aktivitas biji kopi hijau robusta sebagai antioksidan. Metode DPPH ini dipilih karena merupakan metode yang sederhana, mudah, cepat dan peka serta hanya memerlukan sedikit sampel untuk evaluasi aktivitas antioksidan dari senyawa bahan alam (Molyneux P, 2004).

Prinsip pengukuran aktivitas antioksidan secara kuantitatif menggunakan metode DPPH ini adalah adanya perubahan intensitas warna ungu DPPH yang sebanding dengan konsentrasi larutan DPPH tersebut. Radikal bebas DPPH yang memiliki elektron tidak berpasangan akan memberikan warna ungu. Warna akan berubah menjadi kuning saat elektronnya berpasangan. Perubahan intensitas warna ungu ini terjadi karena adanya peredaman radikal bebas yang dihasilkan oleh bereaksinya molekul DPPH dengan atom hidrogen yang dilepaskan oleh molekul senyawa sampel sehingga terbentuk senyawa difenil pikril hidrazin dan menyebabkan terjadinya peluruhan warna DPPH dari ungu ke kuning (Rizkayanti et al., 2017).

Perubahan warna ini akan memberikan perubahan absorbansi pada panjang gelombang maksimum DPPH menggunakan spektrofotometer UV-Vis sehingga akan diketahui nilai aktivitas peredaman radikal bebas yang dinyatakan dengan nilai $\mathrm{IC}_{50}$ (Inhibitory concentration). Nilai $\mathrm{IC}_{50}$ didefinisikan sebagai besarnya konsentrasi senyawa uji yang dapat meredam radikal bebas sebanyak 50\% (Molyneux P, 2004). Semakin kecil nilai $\mathrm{IC}_{50}$ maka semakin tinggi aktivitas antioksidan suatu bahan(Martiningsih et al., 2016).
Hasil penentuan panjang gelombang maksimum DPPH dengan larutan DPPH 40 ppm yang diukur serapannya pada panjang gelombang 400-800 nm adalah $518 \mathrm{~nm}$. Panjang gelombang maksimum ini memberikan serapan paling maksimal dari larutan uji dan memberikan kepekaan paling besar (Rizkayanti et al., 2017).

Hasil aktivitas antioksidan dari filtrat dan endapan maserat air biji kopi hijau robusta dengan seri konsentrasi dapat ditunjukan pada Tabel 1 dan Tabel 2. Pada tabel tersebut menunjukkan adanya peningkatan aktivitas antioksidan berdasarkan konsentrasi larutan sampel. Hubungan antara konsentrasi dengan peningkatan aktivitas antioksidan dapat dilihat dari kurva regresi linier y $=0,176 \mathrm{x}+3,815$ dengan koefisien korelasi $\left(\mathrm{r}^{2}\right)$ sebesar 0,968 (filtrat) dan $y=0,178 x+6,493$ dengan koefisien korelasi $\left(\mathrm{r}^{2}\right)$ sebesar 0,982 (endapan). Hasil ini menunjukkan bahwa metode untuk penentuan aktivitas antioksidan sangat baik untuk digunakan sesuai dengan yang disampaikan Harmita (2004) bahwa jika grafik hasil perhitungan memiliki nilai $r$ mendekati 1 atau sama dengan 1 , maka data hasil penelitian yang diperoleh sangat baik.

Nilai $\mathrm{IC}_{50}$ filtrat dan endapan maserat air biji kopi hijau robusta yang diperoleh dari kurva regresi linier berturut-turut adalah 262,41 ppm dan 244,42 ppm. Filtrat maserat air tergolong memiliki aktivitas antioksidan yang lemah dan endapan maserat air tergolong memiliki aktivitas antioksidan yang sedang. Hal ini diduga karena endapan maserat air mengandung senyawa yang bertanggungjawab pada aktivitas antioksidan dengan konsentrasi yang lebih tinggi dibandingkan dengan senyawa yang terkandung dalam filtrat maserat air. Sehingga, endapan maserat air biji kopi hijau robusta memiliki aktivitas antioksidan yang lebih tinggi dibandingkan dengan filtrat maserat air biji kopi hijau robusta.

Fenol merupakan salah satu senyawa yang berfungsi sebagai antioksidan. Senyawa fenol meliputi flavonoid (turunan inti flavan), cincin kroman (tokoferol) dan lignan. Fenol juga dapat diklasifikasikan ke dalam komponen yang tidak larut seperti lignin dan komponen yang larut seperti asam fenolik, phenylpropanoids, flavonoid dan kuinon. Asam fenolik terdiri dari asam klorogenat, asam kafeat, asam p-kumarat, dan asam vanilat (Silalahi, 2006). Senyawa flavonoid secara in vitro telah terbukti mempunyai efek biologis yang sangat kuat, salah satunya yaitu sebagai antioksidan (Winarsi, 2005). Flavonoid merupakan senyawa yang larut dalam air (Harborne, 1987). Rendahnya aktivitas antioksidan dari maserat air biji kopi hijau robusta diduga karena tidak dilakukan remaserasi untuk memaksimalkan 
proses penyarian agar memperoleh lebih banyak senyawa fenolik dan tidak dilakukan penguapan pelarut untuk mendapatkan ekstrak kental atau pekat. Pemekatan ini berfungsi untuk meningkatkan jumlah senyawa terlarut dengan penguapan pelarut tanpa membuat sampel menjadi kering (Depkes, 2000).

Rendahnya aktivitas antioksidan ini diduga karena adanya senyawa lain dengan kemampuan mereduksi radikal bebas DPPH, yang tidak larut dalam air. Senyawa tersebut yaitu kafein dan trigonelline yang merupakan senyawa alkaloid yang larut dalam pelarut non polar (Aziz et al., 2009; Erviana et al., 2016; Farah, 2012). Dalam penelitian ini, digunakan pelarut air yang hanya mampu melarutkan senyawa fenolik seperti flavonoid dan asam klorogenat yang bersifat polar (Rohman et al., 2006). Sehingga maserat air biji kopi hijau robusta memiliki aktivitas antioksidan yang rendah.

Waktu panen juga mempengaruhi aktivitas antioksidan biji kopi hijau robusta. Dalam penelitian ini, biji kopi hijau robusta dipanen pada siang hari. Seharusnya, pemanenan dilakukan pada pagi hari untuk memperoleh kandungan metabolit sekunder yang maksimal. Sebab, jika dilakukan pada siang hari metabolit sekunder yang berperan sebagai antioksidan akan berkurang ketika sudah terpapar sinar UV dari matahari (Nganggu, 2016). Waktu panen sangat erat hubungannya dengan pembentukan senyawa aktif di dalam bagian tanaman yang akan dipanen. Waktu panen yang tepat pada saat bagian tanaman tersebut mengandung senyawa aktif dalam jumlah yang terbesar (Afandi \& Hertiani, 2015). Asam klorogenat yang terkandung dalam biji kopi hijau juga rentan terhadap panas, oksigen, cahaya, dan kelembapan, karena adanya ikatan tak jenuh dalam molekulnya (Rosliuk et al., 2020) yang kemungkinan menjadi penyebab dari rendahnya aktivitas antioksidan dari maserat biji kopi hijau ini.

\section{SIMPULAN}

Dari hasil uji aktivitas antioksidan dengan metode DPPH maka dapat disimpulkan bahwa maserat air biji kopi hijau robusta di daerah Pupuan memiliki aktivitas antioksidan.

\section{DAFTAR PUSTAKA}

Afandi, K., \& Hertiani, T. (2015). PENGARUH LINGKUNGAN TUMBUH DAN MATURASI DAUN TERHADAP KADAR FENOLIK DAN
FLAVONOID SIMPLISIA DAUN SAMBUNG NYAWA (Gynura procumbens (Lour.) Merr.).

Almoosawi, S., Tsang, C., Davidson, I., Fyfe, L., \& Al-Dujaili, E. A. S. (2010). The effect of green-coffee-bean extract rich in chlorogenic acid on antioxidant status of healthy human volunteers. Proceedings of the Nutrition Society, 69(OCE1), E30. https://doi.org/10.1017/S0029665109992187

Aziz, T., Ratih, C. K. N., \& Asima, F. (2009). Pengaruh Pelarut Heksana dan Etanol, Volume Pelarut, dan Waktu Ekstraksi Terhadap Hasil Ekstraksi Minyak Kopi. Jurnal Teknik Kimia, 16(1), 1-8.

Depkes, R. I. (2000). Parameter Standar Umum Ekstrak Tumbuhan Obat. Departemen Kesehatan Republik Indonesia.

Erviana, L., Malik, A., \& Najib, A. (2016). UJI AKTIVITAS ANTIRADIKAL BEBAS EKSTRAK ETANOL DAUN KEMANGI (Ocimum basilicum L.) DENGAN MENGGUNAKAN METODE DPPH. Jurnal Fitofarmaka Indonesia, 3(2), 164168. https://doi.org/10.33096/jffi.v3i2.217

Farah, A. (2012). Coffee constituents in Coffee: Emerging Health Effect and Disease revention. In Blacwell Publishing Ltd. Blacwell Publishing Ltd. https://www.ift.org/ /media/Knowledge Center/Publications/Books/Samples/IFTPres sBook_Coffee_PreviewChapter.pdf

Farah, A., \& Donangelo, C. M. (2006). Phenolic compounds in coffee. Brazilian Journal of Plant Physiology, 18(1), 23-36. https://doi.org/10.1590/S167704202006000100003

Farhaty, N., \& Muchtaridi. (2016). Tinjauan Kimia Dan Aspek Farmakologi Senyawa Asam Klorogenat Pada Biji Kopi: Review. Farmaka, 14(1), 214-227. http://jurnal.unpad.ac.id/farmaka/article/vie w/10769

Hani, R. C., \& Milanda, T. (2016). Review: Manfaat Antioksidan Pada Tanaman Buah di Indonesia. Farmaka, 14(1), 184-190. https://doi.org/https://doi.org/10.24198/jf.v1 4i1.10735.g5134

Harborne, J. B. (1987). Phytochemical Methods 
Guides in Modern Ways to Analyze Plants. Institut Teknologi Bandung.

Harmita, H. (2004). PETUNJUK PELAKSANAAN VALIDASI METODE DAN CARA PERHITUNGANNYA. Majalah Ilmu Kefarmasian, 1(3), 117-135. https://doi.org/10.7454/psr.v1i3.3375

Kristianto, F. (2017, December). Kopi Robusta Pupuan Asal Bali Siap Mendunia. Bisnis.Com. https://bali.bisnis.com/read/20171206/538/7 71902/kopi-robusta-pupuan-asal-bali-siapmendunia

Martiningsih, N. W., Widana, G. A. B., \& Kristiyanti, P. L. P. (2016). SKRINING FITOKIMIA DAN UJI AKTIVITAS ANTIOKSIDAN EKSTRAK ETANOL DAUN MATOA (Pometia pinnata) DENGAN METODE DPPH. In Prosiding Seminar Nasional MIPA (Vol. 0, Issue 0). https://ejournal.undiksha.ac.id/index.php/se mnasmipa/article/view/10220

Molyneux P. (2004). The use of the stable free radical diphenylpicryl-hydrazyl (DPPH) for estimating anti-oxidant activity. Songklanakarin Journal of Science and Technology, 26(May), 211-219. https://doaj.org/article/56a4ffb8551d457490 $8 \mathrm{eb} 4 \mathrm{ed} 8 \mathrm{a} 264 \mathrm{e} 44$

Nganggu, Y. P. H. (2016). Uji aktivitas antioksidan dan menggunakan metode radikal DPPH $(1,1$ Difenil 2-Pikrilhidrazil) dan penetapan kadar fenolik total fraksi etil asetat ekstrak etanol daun benalu scurrula ferruginea (Jack) danser pada tanaman tabebuia aurea (Manso) Benth. and Hook. f. Ex S. Moore.
Rizkayanti, Diah, A. W. M., \& Jura, M. R. (2017). Uji Aktivitas Antioksidan Ekstrak Air dan Ekstrak Etanol Daun Kelor (Moringa Oleifera LAM). Jurnal Akademika Kimia, 6(2), 125131.

http://jurnal.untad.ac.id/jurnal/index.php/JA K/article/view/9244

Rohman, A., Riyanto, S., \& Utari, D. (2006). Antioxidant activities, total phenolic and flavonoid contents of ethyl acetate extract of Mengkudu (Morinda citrifolia, L) fruit and its fractions. Majalah Farmasi Indonesia, 17(3), 136-142.

Rosliuk, D., Rutkaite, R., Ivanauskas, L., \& Jakstas, V. (2020). Interaction between crosslinked cationic starch microgranules and chlorogenic acid isomers in artichoke and green coffee bean aqueous extracts. Journal of Chromatography B: Analytical Technologies in the Biomedical and Life Sciences, $\quad 1160$ (September), 122385. https://doi.org/10.1016/j.jchromb.2020.1223 85

Silalahi, J. (2006). Makanan Fungsional. Kanisius.

Winarsi, H. (2005). Antioksidan alami dan radikal. Kanisius.

Zuhra, C. F., Tarigan, J. B., \& Sihotang, H. (2008). Aktivitas Antioksidan Senyawa Flavonoid dari Daun Katuk (Sauropus androgunus (L) Merr.). Jurnal Biologi Sumatera, 3(1), 7-10. http://repository.usu.ac.id/bitstream/handle/1 23456789/17562/bio-jan2008-3 (5).pdf;jsessionid=CA3AA0BDBDDB0B47 7081C5E4619B82A7? sequence $=1$ 